\title{
Longitudinal Structural Equation Modeling of Internet Game and Aggression in Children
}

\author{
Joohyun Lee ${ }^{1}$, Kyung Sook Choi ${ }^{2}$ \\ ${ }^{1}$ College of Nursing, Eulji University, Seongnam, South Korea \\ ${ }^{2}$ Red Cross College of Nursing, Chung Ang University, Seoul, South Korea \\ Email: ${ }^{*}$ leejoohyun@eulji.ac.kr
}

Received 3 April 2015; accepted 6 May 2015; published 8 May 2015

Copyright (C) 2015 by authors and Scientific Research Publishing Inc.

This work is licensed under the Creative Commons Attribution International License (CC BY). http://creativecommons.org/licenses/by/4.0/

(c) (†) Open Access

\begin{abstract}
This study aimed to identify the effects of Internet game on levels of aggression in children in the context of individual, familial, and social environments. The subjects were 2844 fourth graders participated in the Korean Youth Panel Survey between 2004 and 2008. Internet game use, the levels of aggression, self-esteem, self-control, stress, depression, attachment to parents, parental control, attachment to teachers, and attachment to peers were measured by 5-point Likert scales. The result showed that gender was the most effective factor influencing the initial level of, the rate of changes, an increase or decrease in the rate of changes in Internet game use and levels of aggression. Boys showed higher levels of Internet game use and aggression than girls. Children with higher self-esteem, self-control and lower stress and depression showed lower levels of Internet game use and aggression. The levels of Internet game use at fourth grade was positively correlated with later increase in the levels of aggression. Also, the faster increase in Internet game use caused faster increase in the levels of aggression later. Based on the results, preventive measures such as limiting the opportunities to access Internet games might be worth to decrease the aggressive behaviors among children.
\end{abstract}

Keywords

Internet, Game, Aggression, Children

\section{Introduction}

The Internet usage rate among Korean youth was nearly 99.9\% in 2012; of this number, at least $98 \%$ of youth are reported to access the Internet for recreational activities, such as playing games and listening to music [1].

${ }^{*}$ Corresponding author.

How to cite this paper: Lee, J. and Choi, K.S. (2015) Longitudinal Structural Equation Modeling of Internet Game and Aggression in Children. Open Journal of Nursing, 5, 426-436. http://dx.doi.org/10.4236/ojn.2015.55046 
About 20\% - 52\% of all male youth have been reported playing Internet game for at least 2 hours per day, and youth who play Internet games for at least 4 hours per day account for approximately $12 \%$ of all male youth [2]. Although the American Psychiatric Association (APA) concluded that there was insufficient evidence to include Internet game addiction as an official mental disorder [3], excessive Internet gaming had led to diverse problems in the physical, psychological, and social domains; in particular, impulsive and aggressive behaviors and tendencies among youth occurring in relation to Internet game addiction had recently become social issues [4]-[7]. However, proposed criteria for "Internet Gaming Disorder" are included in Section 3, Conditions for Further Study. While Internet Gaming Disorder is proposed as a disorder, it is still discussed how much this disorder is caused by the gaming activity itself, or whether it is to some extent an effect of other disorders. Excessive aggression during the teenage years is a problem that must be taken seriously in view of its significant correlation to social success, criminality, and psychosocial function in subsequent middle age [8].

Research has found that severe aggressive tendencies are exhibited by youth who are addicted to Internet games [4]. This aggressive tendency increases with increasing game addiction and game play time [9] [10]. In contrast, in a study, there is no significant correlation between Internet gaming and aggression [11]. In one study, Internet game addiction emerges as youth with pre-existing aggressive tendencies become immersed in Internet games [12]. To precisely identify the relationship between the level of Internet gaming and aggression in youth, an approach is needed that also takes into account the factors that influence this relationship. These factors include demographic variables such as the youth's gender, year in school, economic status, or family structure [13], socio-environmental variables such as parental attachment, parental supervision, teacher attachment, friend attachment, adaptation to school, and peer-group attachment [14] and individual variables such as self-esteem, self-control, impulsivity, depression level, and stress level [15] [16].

Longitudinal research design methods involve the confirmation of changes in multiple factors due to changes in a single factor over time [17]. Such methods can be useful for identifying a correlation over time between Internet gaming level and aggressive tendencies in youth. The latent growth model is an analytical method for longitudinal data analysis [18] [19]. In this analysis, measurement error is controlled when describing the individual growth path of a behavior or attitude. It also has been reported to be very useful in identifying the degree of significance of an individual difference with respect to a change, the factors that directly or indirectly influence the individual difference, and the relationship between a change in one variable and a change in another variable. Therefore, using data from the Korean Youth Panel Survey (KYPS) conducted by the Korea Youth Policy Institute (KYPI) from 2004 to 2008 [20], the author seek to understand changes in aggression with respect to Internet gaming level in childhood and to comprehensively analyze the factors influencing these changes.

The purpose of this study was to identify the changes in the level of Internet gaming in childhood and aggression, select the demographic, individual, familial, and environmental factors that were known to have an impact as influencing factors, establish a longitudinal structural equation model including these factors, and verify the relationships between factors.

\section{Methods}

\subsection{Study Design}

This study was a longitudinal descriptive survey study of the influence of children's level of Internet gaming on aggression, together with demographically related, individual related, family related, and environmentally related factors using KYPS over 5 years.

\subsection{Subjects and Data Collection}

The subjects of this study were 2844 4th grade students and their parents who completed all surveys for inclusion in the 5-year data of the KYPS survey, which was collected and conducted by the KYPI from 2004 to 2008 nationwide [19]. There was no missing data in the first year; however, a total of $14 \%$ of participants dropped out of the survey during the last years.

\subsection{Ethical Consideration}

This study was approved by the Institutional Review Board of the researchers' institution (review number: 2011- 
04-05). It was conducted by downloading questionnaires and source data, which was publicly permitted on the KYPI website.

\subsection{Measurements}

The level of Internet gaming was measured by a 5-point scale from "never (1 point)" to "very often (5 points)", in response to the item "Indicate how much you use Internet for game purposes" in the KYPS survey. Aggression was measured by a 5-point scale index established from "not at all (1 point)" to "very much (5 points)" based on the responses to a total of 6 items in the KYPS survey, including 2 physical aggression items and 4 anger items. A higher score indicates greater aggression. The Cronbach's $\alpha$ for each year was 0.76 (1st year), 0.80 (2nd year), 0.80 (3rd year), 0.80 (4th year), and 0.81 (5th year).

Self-esteem, self-control, stress level, and depression were included as individual factors. Self-esteem was represented by a 5-point index based on responses to 6 items including 3 positive self-esteem items and 3 negative self-esteem items. The Cronbach's $\alpha$ was 0.74 . For self-control, the sum of 6 items such as "how well the child could control him/herself in daily life" was used. The answers were scored on a 5-point scale from "not at all (1 point)" to "very much (5 points)". The Cronbach's $\alpha$ was 0.64 . The stress level was measured by the sum of a total of 16 items measuring stress levels in the child's daily life with regard to schoolwork, relationships with parents, friends, general appearance, and financial situation. A higher score indicated a higher level of stress. The Cronbach's $\alpha$ in this study was 0.90. For the child's level of depression, the sum of a total of 6 items asking about anxiety, depression, and suicidal impulses was used; each item was scored on a 5-point scale from "not at all (1 point)" to "very much (5 points)", so that the higher the total score, the greater the level of depression. The Cronbach's $\alpha$ in this study was 0.79 .

Family related factors included parental attachment and parental supervision. For parental attachment, the total of 6 items measuring emotional closeness to parents on the KYPS survey was used; a higher total score for each item indicated a greater level of parental attachment. The Cronbach's $\alpha$ in this study was 0.76 . Parental supervision was measured by a sum of 4 parental supervision items. A higher score indicated a higher level of parental supervision. The Cronbach's $\alpha$ in this study was 0.80 . Environmentally related factors included teacher attachment and peer-group attachment. Teacher attachment was measured by a total of 3 items asking about the degree of closeness regarding the child's relationship to the teacher. The Cronbach's $\alpha$ in this study was 0.55 . Peer-group attachment was measured by the total of 6 items measuring the child's emotional closeness to school or neighborhood friends. The Cronbach's $\alpha$ in this study was 0.61 .

\subsection{Data Analysis}

Using the SPSS 18.0 and AMOS 17.0 programs, the collected data were analyzed for the general characteristics of the subjects, the descriptive statistics of the research variables, and the reliability and validity of the research instrument itself. To identify the socio-demographic properties of the subjects, frequencies and percentages were calculated, and the means and standard deviations of the research variables were calculated. All items for aggression, self-esteem, self-control, stress level, depression, parental attachment, parental supervision, teacher attachment, and peer attachment were adopted from related previous studies and modified for KYPS survey. Therefore, each item was not exactly same as stated in previous studies. However, all items showed sufficient reliability for this study. Also, to assess the validity of the research instrument, a confirmatory factor analysis for each variable was performed. And all variables showed acceptable $\chi^{2}$ test, degrees of freedom, Tucker-Louis index (TLI), comparative fit index (CFI), and root mean square error of approximation (RMSEA). Pearson correlation matrices for all variables were examined. Changes in Internet gaming level and aggression over time were verified using a latent growth model analysis. A longitudinal structural equation model was designed and validated by setting the relationships between influential factors together with the latent growth model based on the confirmed changes in Internet gaming level and aggression. The $\chi^{2}$ test, degrees of freedom, TLI, CFI, and RMSEA of longitudinal structural equation model were used as indices of model fit.

\section{Results}

Among the subjects of this study, 1524 (53.6\%) were boys, and the majority lived with family (95.3\%) and had siblings (91.0\%); the parents of $43.7 \%$ were college graduates, and $31.0 \%$ had average monthly household incomes in the range of 2 - 3 million Korean won. Table 1 presents the characteristics of the sample. Descriptive 
Table 1. General characteristics of the participants.

\begin{tabular}{|c|c|c|c|}
\hline \multirow{2}{*}{ Characteristics } & Categories & $\mathrm{n}$ & $\%$ \\
\hline & \multicolumn{3}{|c|}{$\mathrm{N}=2844$} \\
\hline \multirow[t]{2}{*}{ Gender } & Male & 1524 & 53.6 \\
\hline & Female & 1320 & 46.4 \\
\hline \multirow[t]{5}{*}{ Type of family } & Parents & 2709 & 95.3 \\
\hline & Single parent & 107 & 3.8 \\
\hline & Remarried & 16 & 0.6 \\
\hline & No parents & 7 & 0.2 \\
\hline & No response & 5 & 0.2 \\
\hline \multirow[t]{3}{*}{ Siblings } & Yes & 2587 & 91.0 \\
\hline & No & 234 & 8.2 \\
\hline & No response & 23 & 0.8 \\
\hline \multirow[t]{5}{*}{ Educational level of father } & Middle school & 159 & 5.5 \\
\hline & High school & 1207 & 42.4 \\
\hline & University & 1244 & 43.7 \\
\hline & Graduate school & 178 & 6.3 \\
\hline & No response & 56 & 2.0 \\
\hline \multirow[t]{5}{*}{ Educational level of mother } & Middle school & 190 & 6.7 \\
\hline & High school & 1695 & 59.6 \\
\hline & University & 853 & 30.0 \\
\hline & Graduate school & 41 & 1.5 \\
\hline & No response & 65 & 2.3 \\
\hline Monthly income & $<100$ & 194 & 6.8 \\
\hline \multirow[t]{6}{*}{ (10,000 won) } & $100-200$ & 789 & 27.7 \\
\hline & $200-300$ & 883 & 31.0 \\
\hline & $300-400$ & 483 & 17.0 \\
\hline & $400-500$ & 287 & 10.1 \\
\hline & $\geq 500$ & 135 & 4.7 \\
\hline & No response & 73 & 2.6 \\
\hline
\end{tabular}

statistics of the Internet gaming, aggression, self-esteem, self-control, depression, stress, parental attachment, parental control, teacher attachment, and peer attachment were provided in Table 2.

\subsection{Changes in Internet Gaming and Aggression}

According to the principles of Bollen and Curren [18], a no-change model, a linear-change model, and a quadratic-change model were each derived using the 5-year data for Internet gaming and aggression. The indices of fit of the three models were compared, and if more than one model showed a good fit, a $\chi^{2}$ difference test was 
Table 2. Descriptive statistics of measured variables.

\begin{tabular}{ccccc}
\hline Variables & M SD & Range & Skewness & Kurtosis \\
\hline Internet game level & & & & -0.663 \\
Year 2004 & $3.47 \pm 1.06$ & $1-5$ & -0.235 & -0.518 \\
Year 2005 & $3.53 \pm 1.05$ & $1-5$ & -0.357 & -0.629 \\
Year 2006 & $3.42 \pm 1.14$ & $1-5$ & -0.357 & -0.780 \\
Year 2007 & $3.34 \pm 1.22$ & $1-5$ & -0.355 & -0.834 \\
Year 2008 & $3.30 \pm 1.25$ & $1-5$ & -0.376 & 0.202 \\
Aggressiveness level & & & 0.052 \\
Year 2004 & $14.11 \pm 4.54$ & $6-30$ & 0.475 & 0.120 \\
Year 2005 & $14.54 \pm 4.72$ & $6-30$ & 0.378 & 0.127 \\
Year 2006 & $15.07 \pm 4.59$ & $6-30$ & 0.347 & 0.015 \\
Year 2007 & $15.54 \pm 4.57$ & $6-30$ & 0.229 & 0.197 \\
Year 2008 & $15.52 \pm 4.60$ & $6-30$ & & -0.100 \\
Self-esteem & & & -0.068 & -0.150 \\
Self-control & $20.95 \pm 4.04$ & $6-30$ & -0.403 & -0.072 \\
Depression & $22.67 \pm 4.12$ & $6-30$ & 0.622 & -0.138 \\
Stress & $12.65 \pm 4.94$ & $6-30$ & 0.680 & -0.192 \\
Parental attachment & $30.29 \pm 11.26$ & $16-73$ & -0.350 & -0.433 \\
Parental control & $22.40 \pm 4.38$ & $6-30$ & -0.300 & -0.263 \\
Teacher attachment & $13.70 \pm 3.83$ & $4-20$ & 0.213 & 0.399 \\
Peer attachment & $8.21 \pm 2.69$ & $3-15$ & -0.520 &
\end{tabular}

conducted to select the model that represented the data best while being somewhat simpler. No-change model hypothesized that there was no significant change in Internet gaming level or aggression over 5 years. The linear-change model presumed two latent variables, the initial value and the rate of change; this model hypothesized linear change over 5 years, setting the variable coefficients for the change rate as $0,1,2,3$, and 4 . The quadratic-change model added latent quadratic change rate variables to the linear-change model, which contained the two latent variables and estimated the initial value and rate of change; this model hypothesized quadratic change over 5 years, setting the variable coefficients for the quadratic change rate to $0,1,4,9$, and 16 .

Comparing the fit of the three models to the 5-year data for Internet gaming level and aggression, both variables were found to have suitable fit indices in the linear-change model and quadratic-change model. A $\chi^{2}$ difference test was therefore conducted and quadratic-change model was selected. The fit of the quadratic change model for Internet gaming level was $\chi^{2}(6, \mathrm{~N}=2844)=25.00$, significant at $p<0.001$, with TLI $=0.98$, CFI $=$ 0.99 , and RMSEA $=0.03$; the fit of the quadratic change model of aggression was $\chi^{2}(6, \mathrm{~N}=2844)=18.85$, significant at $p<0.001$, with TLI $=0.99$, CFI $=0.99$, and RMSEA $=0.03$.

\subsection{Longitudinal Structural Models including Internet Gaming and Aggression}

The latent growth model of Internet gaming level and aggression with the influencing factors had fit indices of $\chi^{2}(115, \mathrm{~N}=2844)=1033.27$, significant at $p<0.001$, with TLI $=0.89$, CFI $=0.93$, and RMSEA $=0.05$, showing that the model was suitable. In this longitudinal structure model, the influential factors such as demographic, individual, family and environmental factors, together with Internet gaming, explained $86.1 \%$ of the change from the initial value of aggression, $43.8 \%$ of the change in the change rate, and $27.9 \%$ of the change in the quadratic change rate of aggression. The influential factors explained $25.0 \%$ of the change from the initial value of the Internet gaming level, $3.9 \%$ of the change in the rate of change, and $0.4 \%$ of the change in the quadratic rate of change. The significance was measured for 24 paths from each influential factor to the initial value, rate of change, and quadratic rate of change of the Internet gaming level and aggression, and for 6 paths from the initial value, rate of change, and quadratic rate of change of the Internet gaming level to the initial value, rate of change, and quadratic rate of change in aggression. Of the total 30 paths, 15 were found to be significant at a significance level of 0.05 . Table 3 presents the result of longitudinal structural models. 
Table 3. Estimates and effects of predictor variables in longitudinal structural model.

\begin{tabular}{|c|c|c|c|c|c|}
\hline \multicolumn{3}{|c|}{ Path } & \multirow{2}{*}{$\begin{array}{c}\text { Estimates } \\
0.44^{* * *}\end{array}$} & \multirow{2}{*}{$\begin{array}{l}\text { S.E. } \\
0.04\end{array}$} & \multirow{2}{*}{$\begin{array}{c}\text { C.R. } \\
18.53\end{array}$} \\
\hline Initial game level & $\leftarrow$ & Gender & & & \\
\hline & & Individual factor & $-0.24^{* * *}$ & 0.02 & -4.08 \\
\hline & & Familial factor & -0.27 & 0.04 & -1.42 \\
\hline & & Environmental factor & 0.29 & 0.16 & 1.27 \\
\hline \multirow[t]{4}{*}{ Changes of game level } & $\leftarrow$ & Gender & $0.16^{* * *}$ & 0.04 & 3.65 \\
\hline & & Individual factor & 0.14 & 0.01 & 1.75 \\
\hline & & Familial factor & 0.12 & 0.03 & 0.46 \\
\hline & & Environmental factor & -0.21 & 0.12 & -0.69 \\
\hline \multirow[t]{4}{*}{ Secondary changes of game level } & $\leftarrow$ & Gender & 0.02 & 0.01 & 0.48 \\
\hline & & Individual factor & -0.06 & 0.01 & -0.74 \\
\hline & & Familial factor & -0.08 & 0.01 & -0.28 \\
\hline & & Environmental factor & 0.12 & 0.03 & 0.38 \\
\hline \multirow[t]{4}{*}{ Initial aggressiveness level } & $\leftarrow$ & Gender & $0.13^{* * *}$ & 0.20 & 4.32 \\
\hline & & Individual factor & $-1.17^{* * *}$ & 0.14 & -11.78 \\
\hline & & Familial factor & -0.21 & 0.29 & -0.73 \\
\hline & & Environmental factor & $0.74^{*}$ & 1.10 & 2.12 \\
\hline \multirow[t]{4}{*}{ Changes of aggressiveness level } & $\leftarrow$ & Gender & $-0.26^{* * *}$ & 0.23 & -4.79 \\
\hline & & Individual factor & $0.70^{* * *}$ & 0.09 & 7.19 \\
\hline & & Familial factor & -0.02 & 0.17 & -0.06 \\
\hline & & Environmental factor & -0.27 & 0.65 & -0.79 \\
\hline \multirow[t]{4}{*}{ Secondary changes of aggressiveness level } & $\leftarrow$ & Gender & $0.17^{*}$ & 0.06 & 2.74 \\
\hline & & Individual factor & $-0.42^{* * *}$ & 0.02 & -4.09 \\
\hline & & Familial factor & 0.09 & 0.04 & 0.28 \\
\hline & & Environmental factor & 0.07 & 0.15 & 0.19 \\
\hline Initial aggressiveness level & & Initial game level & 0.03 & 0.22 & 0.55 \\
\hline Changes of aggressiveness level & $\leftarrow$ & Initial game level & $0.23^{* * *}$ & 0.20 & 3.15 \\
\hline Secondary changes of aggressiveness level & & Initial game level & $-0.22^{* *}$ & 0.05 & -2.67 \\
\hline Changes of aggressiveness level & & Changes of game level & $0.41^{* * *}$ & 0.49 & 4.15 \\
\hline Secondary changes of aggressiveness level & & Changes of game level & $-0.32^{*}$ & 0.13 & -2.59 \\
\hline Secondary changes aggressiveness level & & Secondary changes of game level & $0.15^{* *}$ & 0.23 & 3.24 \\
\hline
\end{tabular}

Above all, 6 factors appeared to have statistically positive influence on the initial value and rate of change in the Internet gaming level. Boys played Internet games significantly more in 4 th grade than did girls $(\beta=0.45, p$ $<0.001$ ), and subsequently during the period up to 5th grade when the Internet gaming level increased, their amount of gaming also significantly increased more rapidly than that of girls $(\beta=0.16, p<0.001)$. From 5th grade on, as the quadratic rate of change in the Internet gaming level declined, no significant difference was apparent between female and male students. Gender factors were also found to have a significant positive effect on the initial value and quadratic change rate of aggression, and a significant negative effect on the rate of change in aggression; there was a significantly higher degree of aggression in boys compared to girls in the 4th grade $(\beta$ $=0.13, p<0.001)$. Subsequently, aggression of boys gradually increased over time compared to girls $(\beta=0.26$, $p<0.001$ ), and in a middle school when as aggression declined, it also declined more rapidly than among girls $(\beta=0.17, p<0.001)$.

For Internet gaming, individual factors were found to have a significant effect only on the initial level; but like gender factors, individual factors had a significant effect on the initial value, rate of change, and quadratic rate of change in aggression. This signified a significantly reduced tendency toward Internet gaming in children with lower levels of depression and stress, and higher levels of self-esteem and self-control in 4 th grade $(\beta=$ $-0.24, p<0.001$ ), but no significant effect on the change in Internet gaming over time. The initial level of aggression was found to be significantly lower in 4th graders with higher levels of self-esteem and self-control and 
lower levels of depression and stress $(\beta=-1.17, p<0.001)$, but the increase in aggression was significantly more rapid $(\beta=0.70, p<0.001)$, and when the rate of increase in aggression declined, it also significantly declined more slowly $(\beta=0.42, p<0.001)$. The familial factors of parental attachment and parental supervision did not have a significant effect on the initial value, rate of change, or quadratic rate of change for either the children's Internet gaming level or their aggression. The environmental factors of teacher attachment and peergroup attachment had a significant positive effect only on the initial value of aggression. The environmental factors had no effect on the initial value, rate of change, or quadratic rate of change in Internet gaming level, or on the rate of change or quadratic rate of change in aggression. This meant that when the teacher attachment and peer-group attachment of a 4 th grade child was high, the level of aggression was significantly higher $(\beta=0.74, p$ $<0.001)$.

\subsection{Longitudinal Relationship between Internet Gaming Level and Aggression}

Under each influential factor, a total of 5 paths were found to be significant with a $p$-value $<0.05$, from among the 6 paths from the initial value, rate of change, and quadratic rate of change in Internet gaming level to the initial value, rate of change, and quadratic rate of change in aggression. The initial value of the Internet gaming level was not found to have a significant effect on the initial value of aggression but did have a significant effect on the rate of change and quadratic rate of change in aggression. This meant that when the level of Internet gaming in 4th graders was high, although it did not have a significant effect on the level of aggression at that time, it did cause aggression to increase more rapidly when aggression increased linearly $(\beta=0.23, p<0.01)$ and caused the rate of increase in aggression to be reduced more slowly when it declined $(\beta=-0.22, p<0.01)$. The rate of change in Internet gaming level was found to have a significant positive effect on the rate of change in aggression and a negatively significant effect on the quadratic rate of change in aggression; this meant that when the Internet gaming level increased linearly, aggression also increased more rapidly $(\beta=0.41, p<0.001)$, and during the period when the rate of increase in aggression was reduced, aggression was also reduced more slowly $(\beta=-0.32, p<0.05)$.

The quadratic rate of change in Internet gaming level was found to have a significant positive effect on the quadratic rate of change in aggression; this indicated that when the Internet gaming level was reduced, aggression also tended to decline quickly $(\beta=0.15, p<0.001)$.

\section{Discussion}

This study sought to explore the effects of the level of Internet gaming in children on aggression. In the result, it was found that there was a significant change over time in the Internet gaming level and aggression of children from the 4th grade of elementary school to the 2nd year of middle school. Also, there were significant individual differences between children in the initial values and changes in Internet gaming level and aggression. It was found that aggression increased from age 10 (4th grade of elementary school) to age 13 (1st year of middle school), and following the 1st year of middle school, the rate of increase was reduced, forming a quadratic curve. This finding corresponded to the finding in previous studies that aggression in youth increased from early to mid-youth, and subsequently declined thereafter [21]. The changes in initial value, rate of change, and quadratic rate of change in aggression were all found to be statistically significant; this meant that the level of aggression in 4th graders differed significantly for each individual child, and there was a significant difference between children in their tendency for aggression to either increase or decrease over time. This finding indicated that even though, on average, aggression among youth began to increase in the early teens and decrease in the midteens and thereafter, different patterns might be exhibited by each individual child. Thus, when approaching problematic activity such as aggressive behavior, an individualized approach program was needed and should be based on the individual child's pattern of change rather than on a program based on the average curve.

This study confirmed that the children's level of Internet gaming increased from 4th to 5th grade of elementary school, and subsequently decreased gradually in the form of a quadratic curve. It has been reported that the age of use of Internet games in Korea has been gradually dropping [1], and that the proportion of high-risk Internet users was twice as great in elementary school as in high school [22]. Thus, this pattern of change in Internet gaming suggested that, when developing strategies for prevention of Internet gaming addiction in children, the preventive effects would be great if an appropriate intervention was made early in childhood. The changes in initial value, rate of change, and quadratic rate of change for Internet gaming level were found to all be statisti- 
cally significant. This indicated that the level of Internet gaming was significantly different for each child in 4th grade and that there was a significant difference between individual child in the increasing or decreasing trend in Internet gaming over time.

In this study, the factors influencing Internet gaming level and aggression in children, based on a review of the literature, were sorted and included in a structural equation model. The included factors were the demographic factor of gender; the individual-related factors of self-esteem, self-control, depression level, and stress level; the family-related factors of parental attachment and parental supervision; and the environmentally related factors of teacher attachment and peer-group attachment. The fit of the longitudinal structure equation model of this study was found to be suitable, and the included factors were thus found to suitably explain Internet gaming level and aggression in children, in particular, to explain $43.8 \%$ of the changes in the initial value of aggression, $43.8 \%$ of the changes in rate of change, and $27.9 \%$ of the changes in quadratic rate of change. Furthermore, the Internet game factor and influencing factors were found to suitably explain the initial values and changes in aggression among children.

Reviewing the effects of each influential factor on Internet gaming level and aggression, it was found that gender had the greatest effect on the initial value and rate of change in Internet gaming in this model. In other words, Boys played significantly more Internet games in 4th grade, and over time, their level of Internet gaming increased significantly more rapidly than that of girls. This finding corresponded to previous research findings that the level of Internet gaming among boys was significantly high, and that when using the Internet, male students mainly played Internet games, whereas female students engaged in activities such as email or chatting [6]. In this study, the level of Internet gaming among boys did decline somewhat over time, but remained comparatively fixed, whereas girls exhibited a continuous decline from 5th grade onward; this trend corresponded to the finding of Hong and No [7] that boys were much more likely than girls to be in the high-usage group rather than the low- or medium-usage groups in Internet gaming. The gender factor was also found to have the second greatest effect on the initial value of aggression; this signified that boys in 4th grade had a significantly greater level of aggression than did girls, which corresponded to the finding of previous research that girls mainly internalized aggression and exhibited relational aggression in puberty and thereafter [23] [24]. In this study, girls exhibited a lower initial value of aggression in 4th grade than did boys, but thereafter, their level of aggression increased significantly faster than boys, and in the first year of middle school and thereafter, they exhibited a greater level of aggression than boys. In particular, the finding that the aggression of girls was high could be explained by its correlation to the aggression index. The aggression items in the KYPS survey consisted of two items on physical aggression and four items on anger. Thus, the proportion of the anger subtype of aggression was relatively high, and since girls expressed anger more as relational aggression than as physical aggression [23], this correlated to a higher aggression score.

The individual-related factors in this study consisted of the child's self-esteem, self-control, depression level, and stress level; these were found to have a significant negative effect on the initial Internet gaming level. This finding suggested that with higher levels of self-esteem and self-control, and lower levels of depression and stress, a child would play Internet games significantly less. It corresponded to a previous report that in the Internet game-addicted group, there were significantly lower levels of self-control and self-esteem and higher levels of depression and stress than in the non-addicted group [9].

In this study's model, individual-related factors were also found to have the greatest effect on the initial value, rate of change, and rate of quadratic change in aggression. Individual factors had a negative influence on the initial value and quadratic rate of change in aggression, and a static influence on the rate of change in aggression; this finding suggested that with higher levels of self-esteem and self-control, and lower levels of depression and stress, the level of aggression in 4th grade was lower and that thereafter it increased more rapidly and declined more slowly. This observation corresponded to previous report that with higher levels of self-esteem and selfcontrol, there were lower levels of psychosocial maladaptation, problematic behaviors, and aggression [25] [26].

Interestingly, it was found that the family-related factors of parental attachment and parental supervision did not have a significant effect on the initial value and rate of change of either Internet gaming or aggression; this finding was different from the result of previous report [6] that factors such as parental attachment, parental nurturing behavior, parental supervision, and effective communication with parents had a significant effect on Internet game addiction and aggressive delinquency. This appeared likely to be related to the fact that the Internet gaming variable used in this study was not the Internet game addiction level diagnosed by an Internet game addiction index, but simply an answer to a question of how often the subject played Internet games, based on a 5 -point scale. Thus, it was recommended that in the future, to more precisely evaluate the effect of familial fac- 
tors on Internet gaming level and aggression, an Internet game addiction index should be used.

The environmental factors of teacher attachment and peer-group attachment were found to have a significant positive effect on the initial value of aggression only. This finding indicated that the level of aggression was higher in 4th graders with high levels of teacher and peer-group attachment. This finding was not consistent with result from previous research that children with high levels of teacher attachment and peer-group attachment had lower levels of aggression [16]. However, this was probably related to the fact that the index of peer-group attachment used in this study was an index measuring only emotional closeness to school friends and neighborhood friends, and additional information on school friends and neighborhood friends was not provided. Youth was a period in which support and encouragement from the peer group played important roles. It has been reported that when engaging in emotional exchanges with delinquent friends in deviant behaviors, there was an increase in externalizing problem behaviors such as aggression in adolescents [27]. Therefore, to measure the correlation between peer-group attachment and aggression more precisely, it was important to identify the relationship with delinquent friends.

In this study, the initial value of the Internet gaming level among children was not found to have a significant correlation with the initial value of aggression, but was found to have a significant positive effect on the rate of change in aggression and to have a significant negative effect on the quadratic rate of change. This indicated that in children who played Internet games extensively in 4th grade, aggression increased more rapidly; subsequently, when the rate of increase in aggression declined, it declined more slowly. This result corresponded to the report by Jeong and Kwan [28] that there was a longitudinal static recursive relationship between Internet gaming and aggression. In their study, they found that an increase in Internet gaming in 2004 led to an increase in aggression in 2005, and an increase in aggression in 2004 led to an increase in Internet gaming in 2005. In their study, the longitudinal recursive relationship was 2 years in length, but in this study, the level of Internet gaming in 4th grade was found to have a significant effect on the pattern of change in aggression through the 2nd year of middle school.

In addition, the rate of change in Internet gaming level was shown to have a significant positive effect on the rate of change in aggression and a significant negative effect on the quadratic rate of change in aggression. This signified that when the Internet gaming level increased, aggression increased rapidly, and during the period in which the rate of increase in aggression declined, it declined more slowly. This relationship signified a positive relationship between the pattern of change in Internet gaming level and the pattern of change in aggression, and corresponded to the finding of previous research that aggression increased with the amount of time spent exposed to violent videos or Internet games [29]. However, that study was a cross-sectional experimental design measuring short-term effects of Internet games on aggression; in contrast, this study was significant in that it measured the effects of the pattern of changes in Internet gaming on the pattern of changes in aggression longitudinally.

Finally, the quadratic rate of change in the Internet game level was found to have a significant positive influence on the quadratic rate of change in aggression. This indicated that the rate of increase in aggression also rapidly declined when the level of Internet gaming declined. This showed that the level of Internet gaming has the same positive effect on aggression, even over a period of 5 years, and signified that there was a need for a systematic effort to block pathways to increase aggression due to increased levels of Internet gaming by developing strategies to reduce the initial level of Internet gaming in youth.

\section{Conclusion}

This study longitudinally observed a causative relationship between Internet games and aggression in youth, which had emerged as a major social problem in Korea. A longitudinal structure model was constructed including influential factors, and significant pathways were investigated for the impact of these influential factors on patterns of changes in Internet game level and aggression over time. The findings of this research present future directions and useful indices for the study of Internet game addiction, violent delinquency, and changes in aggression in children. These findings may also provide useful foundational data for the design of intervention or guidance programs related to the prevention of Internet game addiction.

\section{Acknowledgements}

The authors hereby declare that there was no external funding for this study. 


\section{References}

[1] Korea Internet and Security Agency (2012) Survey on the Internet Use. Korea Internet \& Security Agency, Seoul.

[2] Lee, K.B. (2010) Korean Survey on the Online Game and Family Leisure Activities of Youth and Children in 2009. National Youth Policy Institute, Seoul.

[3] American Psychiatric Association (2015) Conditions for Further Study. Diagnostic and Statistical Manual of Mental Disorders. 5th Edition. http://dsm.psychiatryonline.org/doi/book/10.1176/appi.books.9780890425596

[4] Carnagey, N.I. and Anderson, C.A. (2005) The Effects of Reward and Punishment in Violent Video Games on Aggressive Affect, Cognition and Behavior. Psychological Science, 16, 882-889. http://dx.doi.org/10.1111/j.1467-9280.2005.01632.x

[5] Funk, J.B., Buchman, D.D. and Germann, J.N. (2000) Preference for Violent Electronic Games, Self-Concept and Gender Differences in Young Children Laying Violent Video Games, Desensitization, and Moral Evaluation in Children. American Journal of Orthopsychiatry, 70, 233-241. http://dx.doi.org/10.1037/h0087738

[6] Han, S.H. and Wang, S.J. (2009) Verification of the Moderating Effects of the Variables Related to Adolescents' Addiction to Internet Game and Aggression. The Journal of Educational Research, 7, 51-72.

[7] Hong, S.H. and No, U.K. (2009) Identifying Latent Classes in Early Adolescents' Online Game Time and Testing Determinants of the Classes. Studies on Korean Youth, 20, 411-431.

[8] Huesmann, L.R., Dubow, E.F. and Boxer, P. (2009) Continuity of Aggression from Childhood to Early Adulthood as a Predictor of Life Outcomes: Implications for the Adolescent-Limited and Life-Course-Persistent Models. Aggressive Behavior, 35, 136-149. http://dx.doi.org/10.1002/ab.20300

[9] Kim, K.W. and Boo, J.M. (2006) The Relationship between Flow State, Addiction Orientation in Online Games and Personal Psychological Factors: With Focuses on Self-Esteem, Self-Control, Depression, Aggressiveness and Tendency in Sensation Seeking. The Korea Journal of Counseling, 7, 1169-1187.

[10] Kim, E.J. (2005) Violent Computer Games, Aggressive Delinquency, Internet Delinquency, and Internet Game Addiction in Adolescents. The Korean Journal of Clinical Psychology, 24, 359-377.

[11] Williams, D. and Skoric, M. (2005) Internet Fantasy Violence: A Test of Aggression in an Online Game. Communication Monographs, 72, 217-233. http://dx.doi.org/10.1080/03637750500111781

[12] Stucke, T.S. and Baumeister, R.F. (2006) Ego Depletion and Aggressive Behavior: Is the Inhibition of Aggression a Limited Resource? European Journal of Social Psychology, 36, 1-13. http://dx.doi.org/10.1002/ejsp.285

[13] Lee, K.N. (2006) Relationships between Children’s Aggression and the Variables as Individual, Family, and School Adjustment. Journal of Korean Living Science Association, 15, 31-44.

[14] Allen, P.A., Moore, C., Kupermine, G.P. and Bell, K.L. (1998) Attachment and Adolescent Psychosocial Functioning. Child Development, 69, 1406-1419. http://dx.doi.org/10.2307/1132274

[15] Hale Ill, W.W., VanderValk, I., Akse, J. and Meeus, W. (2008) The Interplay of Early Adolescents’ Depressive Symptoms, Aggression and Perceived Parental Rejection: A Four-Year Community Study. Journal of Youth Adolescence, 37, 928-940. http://dx.doi.org/10.1007/s10964-008-9280-0

[16] Malete, L. (2007) Aggressive and Antisocial Behaviors among Secondary School Students in Botswana: The Influence of Family and School Based Factors. School Psychology International, 28, 90-109. http://dx.doi.org/10.1177/0143034307075683

[17] Campbell, S.B. (2002) Behavior Problems in Preschool Children: Clinical and Developmental Issues. Guilford Press, New York.

[18] Bollen, K.A. and Curran, P.J. (2005) Latent Curve Models: A Structural Equation Perspective. Wiley, Hoboken. http://dx.doi.org/10.1002/0471746096

[19] Duncan, T.E., Duncan, S.C. and Strycker, L.A. (2006) An Introduction to Latent Variable Growth Curve Modeling: Concepts, Issues, and Applications. 2nd Edition, Lawrence Erlbaum Associates, Mahwah.

[20] Lee, K.S. (2004) Korea Youth Panel Survey II Report. National Youth Policy Institute, Seoul.

[21] Karriker-Jaffe, K.J., Foshee, V.A., Ennett, S.T. and Suchindran, C. (2008) The Development of Aggression during Adolescence: Sex Differences in Trajectories of Physical and Social Aggression among Youth in Rural Areas. Journal of Abnormal Child Psychology, 36, 1227-1236. http://dx.doi.org/10.1007/s10802-008-9245-5

[22] Oh, Y.S. (2008) The Impact of Internet Game Addiction on the Melancholy, Offensiveness and Self-Esteem of Adolescents. Journal of Korea Institute of Youth Facility \& Environment, 6, 2-15.

[23] Crick, N.R. and Grotpeter, J.K. (1995) Relational Aggression, Gender, and Social-Psychological Adjustment. Child Development, 66, 710-722. http://dx.doi.org/10.2307/1131945

[24] Martino, S.C., Ellickson, P.L., Klein, D.J., McCaffrey, D. and Edelen, M.O. (2008) Multiple Trajectories of Physical 
Aggression among Adolescent Boys and Girls. Aggressive Behavior, 34, 61-75. http://dx.doi.org/10.1002/ab.20215

[25] Kim, D.K. and Hong, S.H. (2007) Estimating Adolescent's Changes in Overt Aggression: Tests of Effects of Ecological Factors on Individual Differences in the Changes. Survey Research, 8, 21-42.

[26] Seo, M.J. and Kim, K.Y. (2010) Type of Changes in Overt Aggression and Their Predictors in Early Adolescents: Growth Mixture Modeling. Korean Journal of Child Studies, 31, 83-97.

[27] Capaldi, D., Thomas, M., Dishion, J., Stoolmiller, M. and Yoerger, K. (2001) Aggression toward Female Partners by At-Risk Young Men: The Contribution of Male Adolescent Friendships. Developmental Psychology, 37, 61-73. http://dx.doi.org/10.1037/0012-1649.37.1.61

[28] Jeong, K.W. and Kwan, R.H. (2006) Children's Aggressiveness: Is It a Cause or Result of Computer Game? Proceedings of the 3rd Research Forum of Youth Panel Survey, Seoul.

[29] Anderson, C.A. and Dill, K.E. (2000) Video Games and Aggressive Thoughts, Feelings, and Behavior in the Laboratory and in Life. Journal of Personality and Social Psychology, 78, 772-790. http://dx.doi.org/10.1037/0022-3514.78.4.772 